\title{
Design of a Triple-Band h Slot Patch Antenna
}

\author{
Omar Noori, Jalel Chebil, Md. Rafiqul Islam and Sheroz Khan \\ Department of Electrical and Computer Engineering \\ Kulliyyah of Engineering, International Islamic University Malaysia, P.O. Box: 10, 50728 \\ Kuala Lumpur, Malaysia
}

\begin{abstract}
This paper attempts to design a triple band h-slot antenna by using feed line technique. These bands cover GSM mobile phone system (0.9 and $1.8 \mathrm{GHz})$ and ISM band which is used for Bluetooth and wireless local area network bands applications. The CST microwave studio software is used as a tool for simulation. This antenna is an attractive candidate for important applications like mobile phone communication systems, mobile phone jammer application, and so on.
\end{abstract}

Keywords- Microstrip h-slot patch antenna; Return Losses; Gain.

\section{INTRODUCTION}

The past decade has seen a rapid development of wireless communication systems. This continuous trend is bringing about a wave of new wireless devices and systems to meet the demand of multimedia applications. Multi-frequencies and multimode devices such as cellular phones, mobile phone jammer, wireless local area networks (WLAN) and wireless personal area network place several demands on the antennas. Primarily, the antennas need to have high gain, small physical size, and multi bandwidths. Recently there are many demands to design antennas that cover global system mobile (GSM) mobile phone systems and ISM ban systems for some applications. There are two bands for mobile phone 0.9 and 1.8 $\mathrm{GHz}$. The band of $0.9 \mathrm{GHz}$ is extended from $0.88 \mathrm{GHz}$ to 0.96 $\mathrm{GHz}$ for lower band uplink and upper band downlink, while the $1.8 \mathrm{GHz}$ starts from $1.71 \mathrm{GHz}$ to $1.88 \mathrm{GHz}$ for lower band uplink and upper band downlink. Also the mobile has another frequency for another application that is called Bluetooth; Bluetooth radio modules operate in the unlicensed industrial, scientific and medical (ISM) band of $2.4 \mathrm{GHz}$. The (ISM) band ranges from $2 \mathrm{GHz}$ to $2.8 \mathrm{GHz}$ which also include WLAN according to IEEE $802.11 \mathrm{~g}$ standard that extended throughput to up to $54 \mathrm{Mbit} / \mathrm{s}$ using the same $2.4 \mathrm{GHz}$ band. This project needs to meet specific requirement design -such as small size, low cost, low profile, narrowband, gain and directivity sufficient. The microstrip patch antennas are widely used because of their many merits, such as the low profile, light weight, small size and conformity. However, patch antennas have a main disadvantage: narrow bandwidth. Researchers have made many efforts to overcome this problem and many configurations have been presented to extend the bandwidth [1]. The four most popular feeding techniques are the microstrip line, coaxial probe, aperture coupling, and proximity coupling [2] [3]. In this paper a single microstrip line-fed rectangular h-slot patch antenna is proposed to be work with the GSM, Bluetooth and WLAN bands.
Section II is a briefing on present's antenna design. then, feeding techniques is in Section III, while Section Iv presents triple band patch antenna Section $\mathrm{v}$ shows the results and discussion. Finally, conclusion is given in Section VI.

\section{MICROSTRIP ANTENNA DESIGN}

There are many different shapes of microstrip antenna such as rectangular, square, dipole, circular etc. The rectangular patch is considered the most widely used configuration. It is very easy to analyze using both the transmission-line and cavity models, which are most accurate for thin substrates [4]. In this paper the rectangular patch antenna and transmission line method are used to approximate the dimensions to design an antenna and to match the radiating patch and the transmission line impedance. This paper started with single rectangular patch antenna after that the $h$ slot inserts in the patch. The value of parameters like the dielectric constant of the substrate $\left(\varepsilon_{\mathrm{r}}\right)$, the resonant frequency $\left(f_{\mathrm{r}}\right)$, and the height of the substrate $(\mathrm{h})$ should be known when The design patch antenna is requested. The design procedures are as follows [5]:

First the width (W) is determined from

$W=\frac{1}{2 f_{r} \sqrt{\mu_{o} \varepsilon_{0}}} \sqrt{\frac{2}{\mathcal{E}_{r}+1}}=\frac{c_{0}}{2 f_{r}} \sqrt{\frac{2}{\mathcal{E}_{r}+1}}$

where $c_{0}$ is the free-space velocity of light

Then one can determine the effective dielectric constant of the microstrip antenna using the following equation:

$\mathcal{E}_{r e f f}=\left\{\begin{array}{l}\frac{\mathcal{E}_{r}+1}{2}+\frac{\mathcal{E}_{r}-1}{2}\left[1+12 \frac{h}{w}\right]^{-\frac{1}{2}} \text { for } \mathrm{w} / \mathrm{h} \geq 1 \\ \frac{\mathcal{E}_{r}+1}{2}+\frac{\mathcal{E}_{r}-1}{2}\left[1+12 \frac{h}{w}\right]^{-\frac{1}{2}}+0.041\left[1-\sqrt{\frac{w}{h}}\right] \text { for } \mathrm{w} / \mathrm{h}<1\end{array}\right.$

Afterwards the extension of the length $\Delta \mathrm{L}$ can be determined using

$\Delta L=0.412 \mathrm{~h} \frac{\left(\boldsymbol{\varepsilon}_{\text {reff }}+0.3\right)\left[\frac{w}{h}+0.364\right]}{\left(\boldsymbol{\varepsilon}_{\text {reff }}-0.258\right)\left[\frac{w}{h}+0.8\right]}$ 
Table 1 Comparison of Feed Techniques [3]

The actual length of the patch can now be determined by using this equation:

$$
L=\frac{c_{0}}{2 f_{r} \sqrt{\mathcal{E}_{\text {reff }}}}-2 \Delta L
$$

From these equations that mentioned above, we can see that the resonant frequencies are inversely proportional to the width, length and dielectric constant substrate.

\section{FEEDING TECHNIQUES}

Microstrip patch antennas can be fed by a variety of methods. These methods can be classified into two categoriescontact and non-contact. In the contact method, the RF power is fed directly to the radiating patch using a connecting element such as a microstrip line. In the non-contact scheme, electromagnetic field coupling is done to transfer power between the microstrip line and the radiating patch [6] [7]. The four most popular feed techniques used are the microstrip line, coaxial probe (both contact schemes), aperture coupling and proximity coupling (both non-contact schemes) [8].

The microstrip line feed is used here. In this type of feed technique [3], a conducting strip is connected directly to the edge of the microstrip patch. The conducting strip is smaller in width as compared to the patch and this kind of feed arrangement has the advantage that the feed can be etched on the same substrate to provide for a planar structure. To match the impedance of the feed line to the patch without the need for any additional matching element can be done by the inset cut in the patch. This is achieved by correctly controlling the inset position. Hence this is an easy feeding scheme, since it provides ease of fabrication and simplicity in modeling as well as impedance matching. However as the substrate thickness increases, dielectric constant decreases, radiation loss, surface waves and spurious feed radiation increases, which for practical designs limit the bandwidth (typically 2-5\%). The comparison between the techniques feeding is illustrated in Table 1.

\section{TRIPLE BAND PATCH ANTENNA}

There are some works that have been done in this field (Triple-band patch antenna) but for different applications and with different resonant frequency. Some of these works have been achieved the multi-band microstrip patch antennas with the three-band central frequencies. Dong -hee and etal used single patch antenna with c-shaped slots of letter in the excited patch and combining the parasitic patch and excited patch in $U$ shape of letter on the three-layered structure.Therefore, the proposed antennas can be applied for various kinds of a mobile communication applications, including a MIMO (MultipleInput Multiple-Output) systems [9]. Mohammed and etal presented in their paper a new design multi-band patch antenna, based on the U-shape and characterized by shorting; it has been

\begin{tabular}{|c|c|c|c|c|}
\hline Characteristics & $\begin{array}{c}\text { Microstrip } \\
\text { Line Feed }\end{array}$ & $\begin{array}{c}\text { Coaxial } \\
\text { Feed }\end{array}$ & $\begin{array}{c}\text { Aperture } \\
\text { Coupled } \\
\text { Feed }\end{array}$ & $\begin{array}{c}\text { Proximity } \\
\text { Coupled } \\
\text { Field }\end{array}$ \\
\hline $\begin{array}{c}\text { Spurious Feed } \\
\text { Radiation }\end{array}$ & More & More & More & More \\
\hline Reliability & Better & $\begin{array}{c}\text { Poor due } \\
\text { to } \\
\text { soldering }\end{array}$ & Good & Good \\
\hline $\begin{array}{c}\text { Ease of } \\
\text { fabrication } \\
\text { and } \\
\text { drilling } \\
\text { needed }\end{array}$ & Easy & $\begin{array}{c}\text { Solderignment } \\
\text { required }\end{array}$ & $\begin{array}{c}\text { Alignment } \\
\text { required }\end{array}$ \\
\hline $\begin{array}{c}\text { Impedance } \\
\text { matching }\end{array}$ & Easy & Easy & Easy \\
\hline $\begin{array}{c}\text { Bandwidth } \\
\text { (achieved with } \\
\text { impedance } \\
\text { matching) }\end{array}$ & $2-5 \%$ & $2-5 \%$ & $2-5 \%$ & $13 \%$ \\
\hline
\end{tabular}

presented for the applications of wireless communication to current $0.9,2.2$ and $5 \mathrm{GHz}$ [10]. The others have presented a novel $\mathrm{H}$-Shaped reconfigurable microstrip patch antenna fed by a Grounded Coplanar Waveguide (GCPW) for wireless applications. The antenna design relies on the ability to select the number of operating frequencies electronically by using a varactor diode Global Position System (GPS), a dual band mode to cover GPS and Global System for Mobile communications (GSM1900) or a three-band mode to cover GPS, GSM1900 and Bluetooth or WLAN [11]. In this paper a triple band $h$ slot antenna is designed for the GSM900, GSM1800 and ISM bands. In the first stage, a single fed-line rectangular patch antenna is designed for a single resonant frequency at $1.86 \mathrm{GHz}$ using a substrate with dielectric constant $\varepsilon_{\mathrm{r}}=5.2$ and height $1.6 \mathrm{~mm}$. Fig. 1 shows the important parameters of the rectangular patch. Then, the $h$ slot is inserted on the centre of the patch as shown in Fig. 2 with dimensions $\mathrm{w}_{1}, \mathrm{w}_{2}$, and $\mathrm{w}_{3}$. The CST microwave studio is used to simulate the patch antenna and also to determine the optimum values for $\mathrm{w}_{1}, \mathrm{w}_{2}$, and $\mathrm{w}_{3}$.

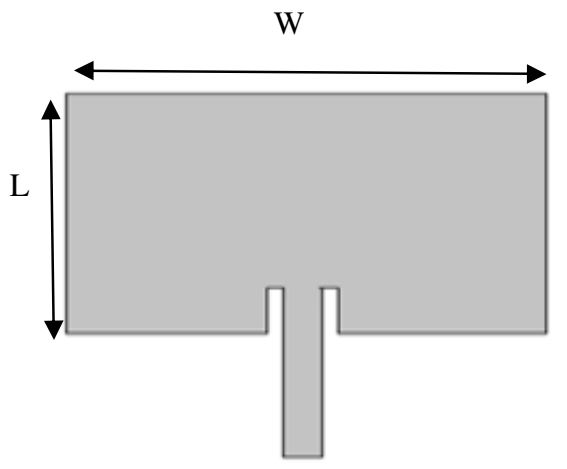

Fig 1 Patch antenna for one resonant frequency 


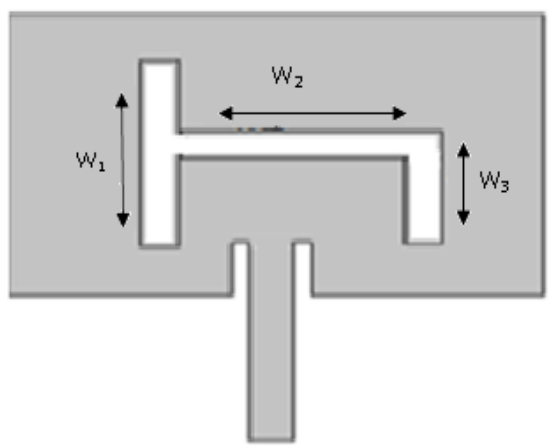

Fig 2 h slot Patch antenna for triple resonant frequency

\section{RESULT AND DISCUSSION}

The dimensions of the single fed-line rectangular patch antenna are determined using equations (1) to (4) and the dimensions results are shown in Table 2, and the resonant frequency shown in Fig.3. When the $h$ slot inserted inside the patch, the two variable $(n, l)$ was used where $n$ represent change in width for $w_{1}, \mathrm{w}_{2}$ and $\mathrm{w}_{3} . l$ represent change in length for $\mathrm{w}_{2}$ after that the CST software was used to determine the optimum values for $\mathrm{w}_{1}, \mathrm{w}_{2}$, and $\mathrm{w}_{3}$. Fig 4 shows the resonant frequency for this optimization, subsequently the best dimensions that achieve the requested triple band frequency have been chosen Table 3 shows that and Fig 5 shows the triple band that are requested for this paper. The gain and return losses for these frequencies is illustrated in Table 4. Fig 6(a-c) shows the radiation pattern in 2D and for these bands $0.9,1.8$ and $2.4 \mathrm{Ghz}$ respectively.

Table 2 Parameters Dimensions without Slot

\begin{tabular}{|c|c|c|}
\hline Parameter & Width(mm) & Length(mm) \\
\hline Substrate & 80 & 86 \\
\hline Ground & 80 & 86 \\
\hline Patch & 52 & 34.44 \\
\hline Feed Line & 2.704 & 38.36 \\
\hline
\end{tabular}

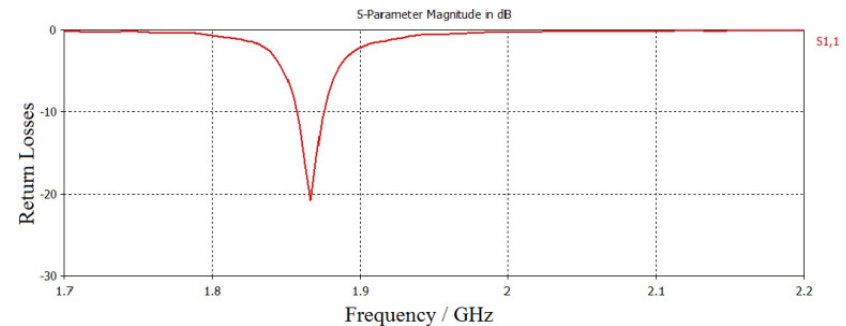

Fig 3 Resonant Frequency without h slot

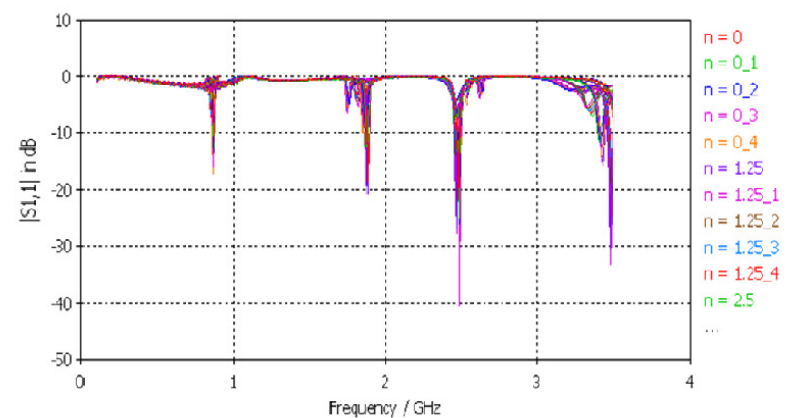

Fig 4. Resonant Frequency with h slot By manipulating the values of w1, w2 and $\mathrm{w} 3$.

Table 3 Parameters Dimensions for $\mathrm{h}$ Slot patch antenna

\begin{tabular}{|c|c|c|}
\hline Parameter & Width $(\mathrm{mm})$ & Length $(\mathrm{mm})$ \\
\hline Substrate & 80 & 86 \\
\hline Ground & 80 & 86 \\
\hline Patch & 54 & 35.72 \\
\hline W1 & 5 & 26 \\
\hline W2 & 20 & 5 \\
\hline W3 & 5 & 16 \\
\hline
\end{tabular}

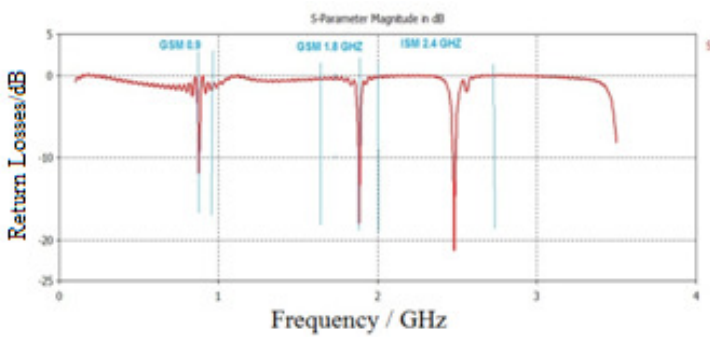

Fig 5. Triple Resonant Frequency with h slot

Table 4 Gain and return losses
\begin{tabular}{|c|c|c|}
\hline $\begin{array}{c}\text { Field monitor } \\
\text { (GHZ) }\end{array}$ & Gain (dB) & $\begin{array}{c}\text { Return losses } \\
\text { (dB) }\end{array}$ \\
\hline 0.9 & 8.783 & -11.618 \\
\hline 1.8 & 5.863 & -18.538 \\
\hline 2.4 & 7.903 & -21.533 \\
\hline
\end{tabular}




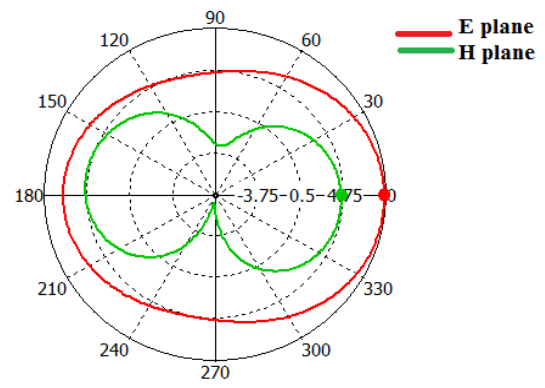

(a)

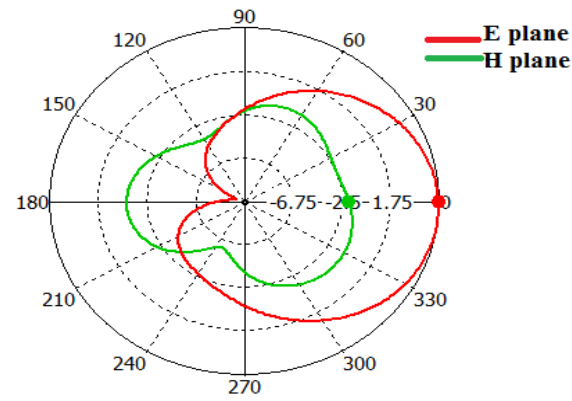

(b)

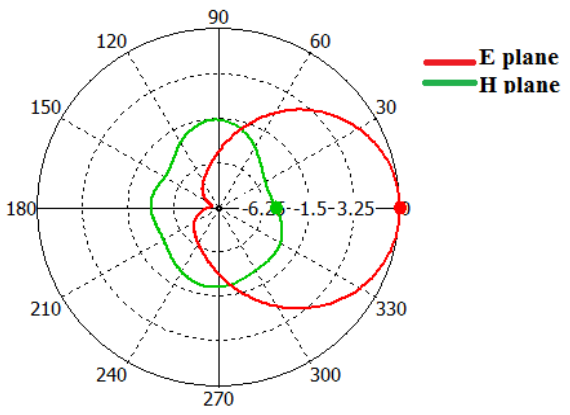

(C)

Fig. 6 simulation gain radiation pattern in 2D for (a) $0.9 \mathrm{GHz}$ (b) $1.8 \mathrm{GHz}$ (c) 2.4 GHZ respectively.

\section{CONCLUSIONS}

In this paper, the small triple-band h-slot microstrip patch antennas are designed. The parameters, gain, return losses, copolar and cross-polar are shown. The feed line technique and CST microwave studio software for simulation are used. The gain and return losses were good for these bands. The antenna is designed to be used in multi-band mobile phone systems or jammer system applications, covering the GSM and ISM bands.

\section{ACKNOWLEDGMENT}

The authors are very grateful to Research Management Centre, International Islamic University Malaysia for supporting the project by Endowment research grant.

\section{REFERENCES}

[1] Dong-Hee Park; Yoon-Sik Kwak, "Design multi-Band Microstip patch antenna for wireless terminals", IEE, Jeju ,2008.

[2] D. M. Pozar, "Microstrip Antennas," Proc. IEEE, Vol. 80, No. 1, pp. 79-81, January 1992.

[3] G. Jegan . A.Vimala juliet . G. Ashok kumar, "Multi Band Microstrip Patch Antenna for Satellite Communication” 2010 IEEE.

[4] D. H. Schaubert, D. M. Pozar, and A. Adrian, "Effect of Microstrip Antenna Substrate Thickness and Permittivity: Comparison of Theories and Experiment," IEEE Trans. Antennas Propagat., Vol. AP-37, No. 6, pp. 677-682, June 1989.

[5] Constantine A. Balanis, "Antenna Theory Analysis And Design" WileyInterscience, 2005

[6] W. Weichung, C.T.M. Choi and w. Shuming "Optimal Feed Positions for Microstrip fed Rectangular Patch Antennas by Finite Difference Time Domain Analysis", Microwave conference 2001. Proceedings of APMC 2001, Taipei, Taiwan. 3-6 December 2001.

[7] B.T.P.Madhav, PROF. Vgkm Pisipati, K V L Bhavani, P.Sreekanth P.Rakesh Kumar. "Rectangular Microstrip Patch Antenna On Liquid Crystal Polymer Substrate" Journal of Theoretical and Applied Information Technology 2005 - 2010 JATIT.

[8] A. T. Kazi, Md. Bellal Hossain, Md. Javed Hossain, "Designing a high bandwidth Patch Antenna and comparison with the former Patch Antennas" Canadian Journal on Multimedia and Wireless Networks Vol. 2, No. 2, April 2011.

[9] P. Dong-Hee; K. Yoon-Sik, "Design Multi-Band Microstrip Patch Antennas for Wireless Terminals" 2007IEEE.

[10] A. B. Mohamed, E. Fatiha, B. Mohamed, M. Ahmed, "Design and Dosimetry of a New Multi-band Patch Antenna for Wireless Communications", 2009 IEEE.

[11] H. F. AbuTarboush1, R. Nilavalan1, K. M. Nasr2, H. S. Al-Raweshidy1 and D. Budimir3, "A Reconfigurable H-Shape Antenna for wireless Applications" 2010 IEEE. 